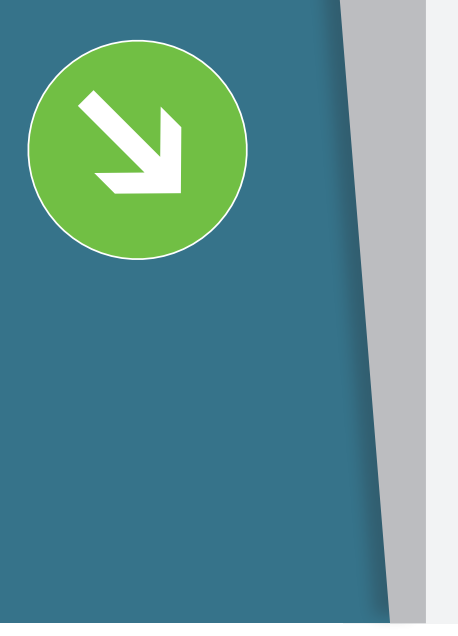

\title{
ОБОРУДОВАНИЕ - ФУНДАМЕНТ ДЛЯ ПОВЫШЕНИЯ ПРОИЗВОДИТЕЛЬНОСТИ ТРУДА
}

\author{
Николай САМАРИН
}

Производительность труда - один из ключевых показателей конкурентоспособности экономики страны, и последние несколько лет Правительство Российской Федерации проводит последовательную политику по повышению этого показателя, устранения разрыва с государствами-лидерами мировой экономики. Решение этой задачи требует: повышения квалификации персонала, модернизации парка оборудования, внедрения более эффективных технологий производства, перехода к «Индустрии 4.0».

Существует множество методик оценки производительности труда, в том числе фактическая производительность труда, наличная производительность труда и т.д. Условимся, что под производительностью понимаем годовую выручку предприятия, отнесенную к численности персонала.

Из общения с руководителями и собственниками машиностроительных предприятий можно выделить то, что при первом упоминании о повышении производительности труда в их воображении возникают производства, наполненные роботами, которые автоматически выполняют поставленные задачи, а производительность от этого растет не по дням, а по часам (рис. 1).

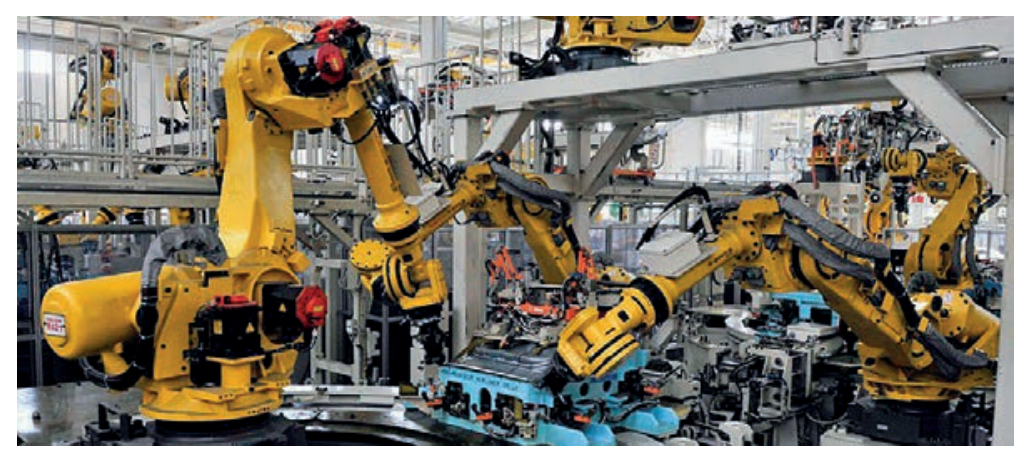

Puc. 1. Роботизированный сварочный комплекс
Действительность российской машиностроительной и металлообрабатывающей отраслей в 2019 году значительно отличается от того, как аналогичные отрасли работают в Германии, Японии, Италии или США. Она характеризуется качеством заготовок (большие припуски, однородность материала, химический состав), дорогими кредитными ресурсами, задержками с платежами от заказчиков, несовершенством налоговой и административной системы, уровнем подготовки профессиональных кадров, обширным взаимодействием с государственными предприятиями.

По мнению директора Центра трудовых исследований ВШЭ Владимира Гимпельсона, у нас очень распространено представление, что проблема заключается в отсутствии современных технологий, и если купить новый станок, производственную линию или завод - у нас сразу вырастет производительность. Такое представление очень наивно.

Эффективное применение средств автоматизации технологических процессов требует практически идеальных исходных условий: серийности производства; великолепного качества исходного материала; высокой квалификации кадрового состава, который может программировать, использовать, обслуживать автоматизированную линию; значительного инвестиционного бюджета, что в некоторых случаях оправдано, но в большинстве - нет.

Большинство мелких и средних машиностроительных предприятий используют более чем на 50\% универсальное (без числового программного управления) оборудование для механической обработки, простые приспособления для сварки и сборки изделий (рис. 2, 3).

Приобретение, подготовка производства к использованию роботизиро- 


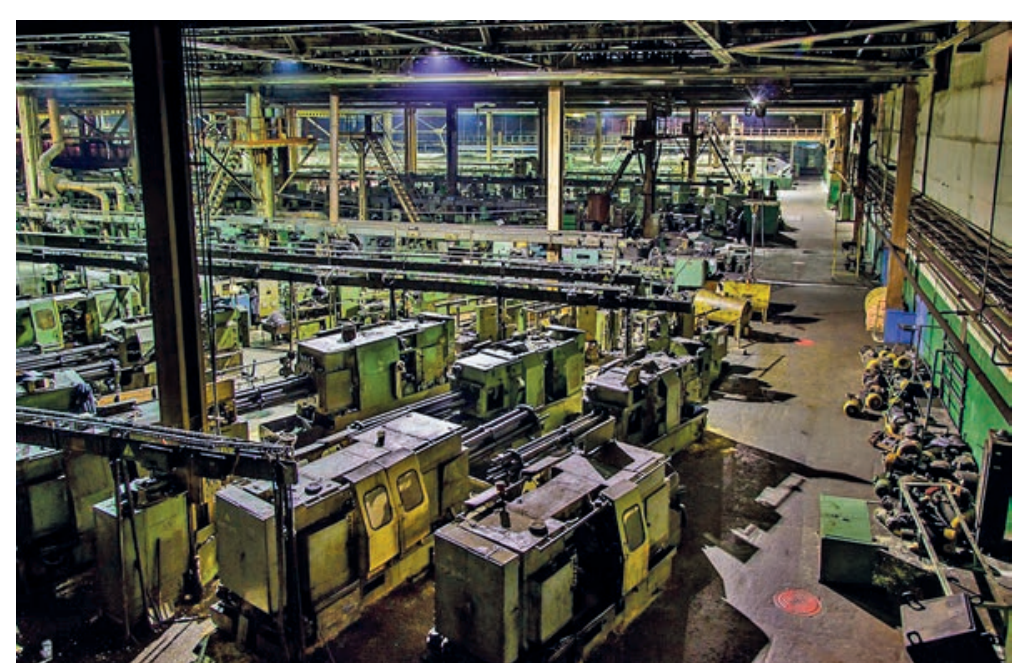

Puc. 2. ЧТЗ Уралтрак (г. Челябинск), 2013 год - участок токарных автоматов

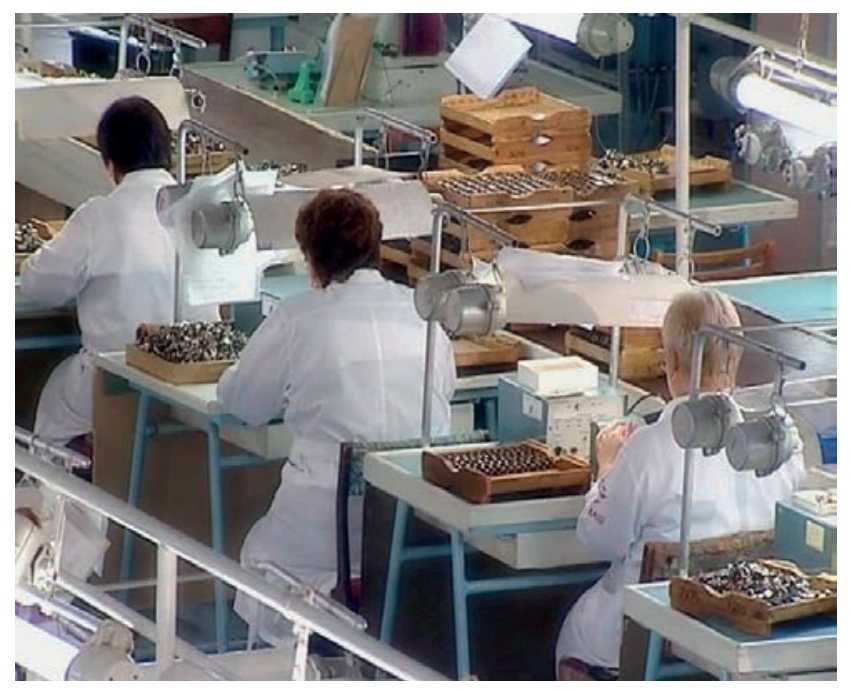

Puc. 3. АО «ВП0 «Точмаш» (г.Владимир) - участок сборки

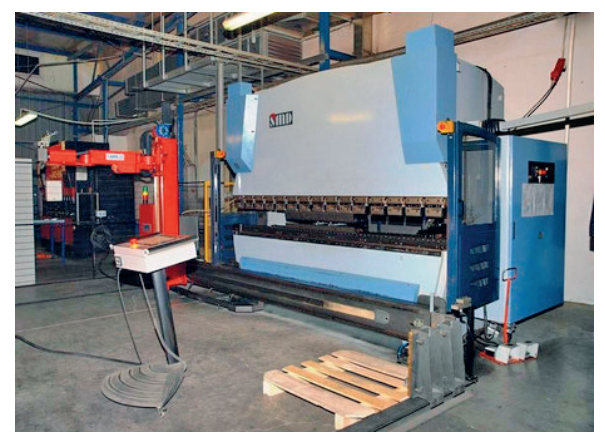

Puc. 4.

Листо-

гибочный пресс с ЧПУ SMD PBH 110$3100-4 C+$ робот ANTIL

ванной линии, любого комплекса автоматизированных производственных систем не всегда оправданы экономически и действительно необходимы. Вот пример из практики применения средств автоматизации: заказчик, компания-изго- товитель металлических дверей приобрела комплекс, состоящий из листогибочного пресса с ЧПУ и робота для загрузки-выгрузки заготовок и деталей (рис. 4).

Не получив в нужном объеме заказ по противопожарным металлическим дверям, на который рассчитывала компания, она переключилась на менее серийную (единичную), специализированную, но более дорогостоящую продукцию. Робот-манипулятор просто не использовался и простаивал из-за сложности программирования, обширной номенклатуры деталей. Манипулятор был продан, высвободившиеся средства вложены в приобретение еще одного - простого - листогибочного пресса, организована работа в две смены, в результате инвестиции окупились за один год!

Зачастую анализ текущих и ближайших производственных задач, планов получения новых заказов, откровенное обсуждение достоверных «узких мест» на производстве дает быстрый положительный результат: для того чтобы победить конкурентов в своем сегменте рынка заказчику достаточно оптимально выполнить точечное перевооружение на одном или нескольких участках, что обеспечит приток новых заказов, специалистов, технологий. Очень часто такие комплексные задачи технического перевооружения решаются приобретением даже одного многофункционального обрабатывающего центра.

Яркий пример - диалог с производственной компанией, клиентом компании КАМИ, из сферы метизного производства (рис. 5) выявил следующие проблемы: по мнению специалистов завода, для выполнения потенциального заказа необходимо приобретение токарного центра с ЧПу для токарных операций, фрезерного центра с ЧПУ с поворотным индексным столом для выполнения фрезерных операций. Это влекло за собой потенциальные затраты на приобретение оборудования нормального класса точности в сумме не менее 10 млн руб., подготовку фундамента на участке

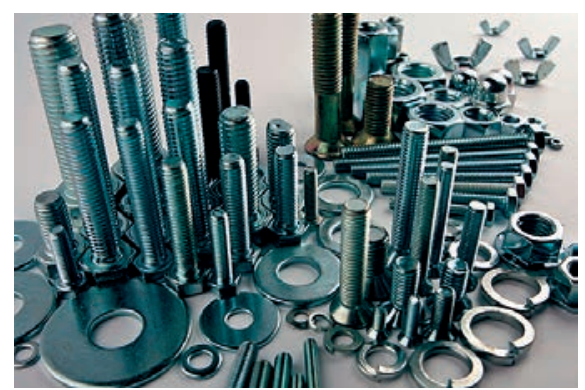

Puc. 5.

Метизная

продукция 


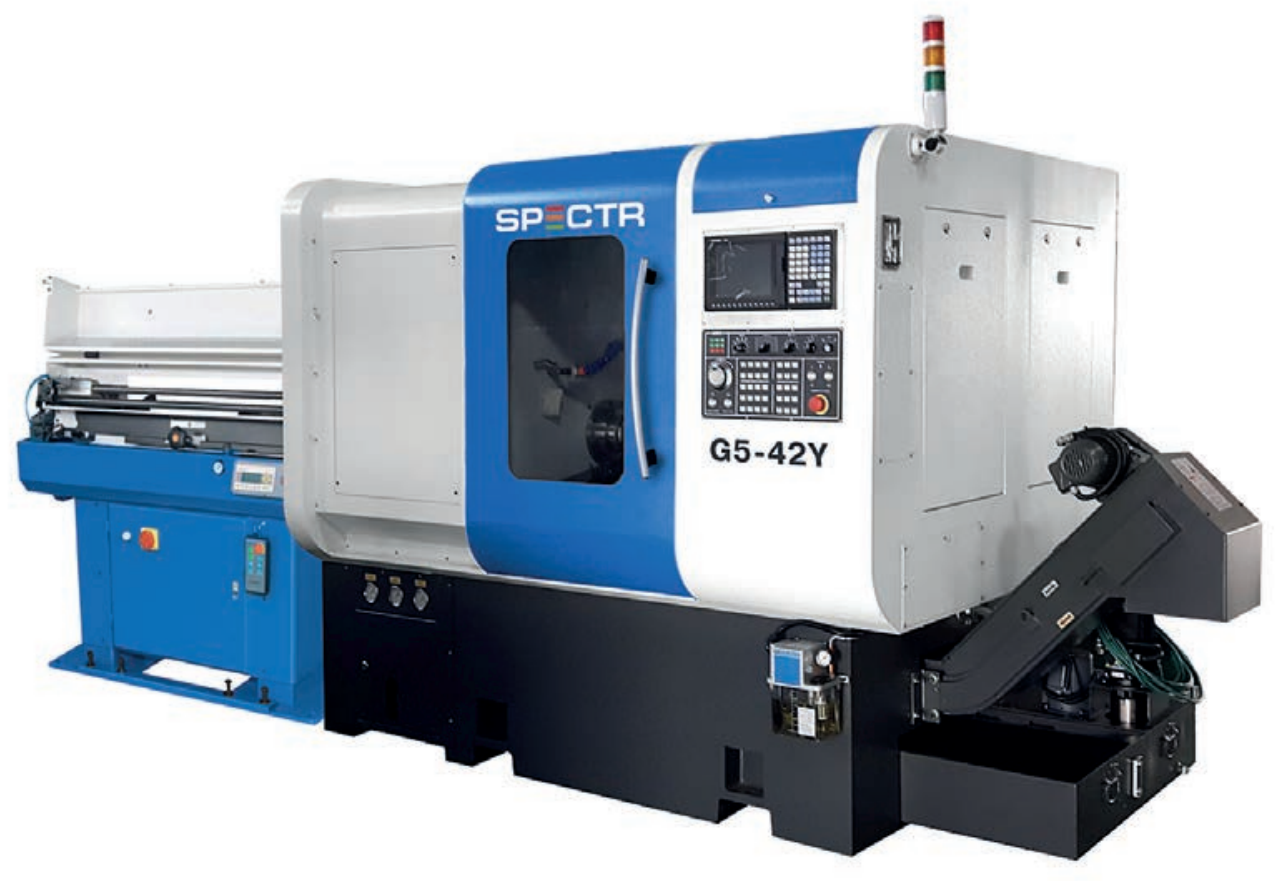

PUc. 6. Токарно-фрезерный обрабатывающий центр с ЧПУ SPECTR модели G5-42Y (производства Тайвань)

$50 \mathrm{~m}^{2}$, дополнительные электрические мощности на 40 кВа, поиск и обучение двух профильных операторов, подготовку операционных карт на два станка и т. д.

После обсуждения всех производственных приоритетов со специалистами КАМИ, для решения задач был предложен принцип концентрации операций механической обработки изделий. К приобретению рекомендован токарно-фрезерный обрабатывающий центр с ЧПУ SPECTR модели G5-42Y (производства Тайвань) (рис. 6), который, кроме токарного, оснащен фрезерным инструментом, а также дополнительной осью $Y$. Как итог, бюджет на техническое перевооружение был сокращен ровно в два раза, в таком же соотношении были уменьшены площади для нового оборудования и штат персонала на данном участке, а полный цикл изготовления изделия сокращен в 3,5 раза. Расширена номенклатура выпускаемых изделий за счет более широкого функционала станка.

Качество продукции было повышено за счет сокращения количества технологических установов, повышенного класса точности станка, при этом были достигнуты лучшие шероховатости поверхности до Ra 0,4. Сокращено время загрузки заготовок, благодаря применению системы подачи прутка и уловителя готовых деталей.

Среди клиентов КАМИ можно обнаружить тысячи положительных примеров эффективных перевооружений п р о и з в о д с т в, выхода заказчиков на новые показатели производительности труда и расширения номенклатуры. Повышение доходности их бизнеса демонстрирует, что просто станок или автоматизированный комплекс - это фундамент для техн и ч е с к о г о перевооружения п ре д п и я тия , но этого недостаточно. Крайне важно иметь возможность получения полного набора сервисов и услуг при покупке оборудования - это залог эффективного перевооружения, ведущего к повышению производительности труда!

КАМИ, как наиболее опытный поставщик, работающий более 28-ми лет на рынке поставок металлообрабатывающих станков, предлагает не только поставку оборудования, но и технологический аудит производств, шеф-монтажные работы, инструктаж и расширенное обучение специалистов с передачей навыков профессиональных операторов и инженеров-наладчиков, подбор режущего инструмента и режимов резания, подготовку технологических карт для типовых деталей, технологическое и сервисное сопровождение станка после внедрения в производство. Такие дополнительные возможности позволяют предприятию - заказчику станка - работать с подготовленным персоналом, немедленно получать от станка готовые детали и, соответственно, выручку, увеличить эффективность производства и, как следствие, до минимума сократить срок окупаемости нового приобретения.

Доверьте экономически эффективное повышение производительности труда для вашего металлообрабатывающего производства профессионалам КАМИ: www.stanki.ru.

САМАРИН Николай Николаевич -

генеральный директор «КАМИ-Металл» 
